\title{
Care of Women with Terminal Pelvic Cancer
}

\author{
J. K. RUSSELL,* M.D., F.R.C.O.G. ; MARY R. MILLER, † M.B., CH.B.
}

Brit. med. F., 1964, 1, 1214-1216

The limitations of radical surgical and radiotherapeutic techniques have long been apparent and it is understandable that interest in gynaecological cancer should pass increasingly to early detection and the prevention of invasive cancer. In particular this applies to cervical neoplasm, but it will be many years before the female population at risk is effectively screened by means of exfoliative cytology. Gynaecological clinics, at least in this century, will continue to deal with cases of pelvic cancer for whom the outlook, in terms of five-year survival, is poor. At least half and in some forms of cancer as many as three-quarters of these patients die within five years.

In the Royal Victoria Infirmary between 100 and 120 new patients with pelvic cancer are admitted to the gynaecological department each year, and after radiotherapeutic or surgical treatment their progress is checked regularly at a combined follow-up clinic. Many develop recurrent growths and other serious complications, and we have long been aware of the need for special study of the formidable social and medical problems faced by these women. Since October 1960 one of us (M. R. M.) has kept these particular patients under close and continuous observation during the period of terminal illness, and we report here the result of our investigation.

\section{Investigation}

The study began in October 1960 and lasted until March 1963. During this period 295 cases were admitted to the department for treatment and 52 of these patients died. A further 76 patients, treated before October 1960 and suffering from recurrence or other serious complications, were selected for special study and 41 died. One of us (M. R. M.) acted purely as an observer, attending ward rounds and the weekly combined follow-up clinic with gynaecologists and radiotherapists. When a patient's condition was deteriorating arrangements were made through the family doctor for M.R.M. to visit the home ; it was usual, after the initial introduction, for several visits to be paid. Family doctors, district nurses, and relatives provided us with much useful information. Patients were drawn from the densely populated Tyneside conurbation and from scattered rural areas throughout the north-east of England; all social classes were represented.

\section{Readmission of Patients to Royal Victoria Infirmary}

During the period of the study 85 women with gynaecological cancer were readmitted to the Royal Victoria Infirmary, mainly to the gynaecological ward, for the investigation of suspicious symptoms or the relief of serious incapacities. The reasons for these readmissions are shown in Table I. Although some spent only a day or two in hospital many were in for two or three weeks, and nine spent from one to three months in the gynaecological ward; as a group these patients make a considerable call on the available beds. It is not our purpose in this article to examine critically the value of the various investi-

\footnotetext{
* Professor of Obstetrics and Gynaecology, University of Newcastle upon Tyne ; Consultant Gynaecologist, Royal Victoria Infirmary.

† Senior Research Associate in Obstetrics and Gynaecology, University of Newcastle upon Tyne. Supported by a grant from the North of England Council of the British Empire Cancer Campaign.
}

gations and procedures that were carried out, but they seemed to us to be justified in the presence of such serious complications.

Patients willingly accepted the need for investigation and treatment when first admitted, and we noted a readiness to come back into hospital in the face of such symptoms as weight loss, vaginal bleeding, pain, and upset in the gastro-intestinal or renal tracts. But many reached a stage at which they became reluctant to come back into the ward; possibly they realized that the hospital had then little to offer. In the terminal stages the management of certain complications was associated with difficult moral issues. Several patients were readmitted because of heavy vaginal or rectal bleeding due to widespread pelvic recurrence. We understand the distress that this bleeding caused the patients, their relatives, and family doctors, but the decision whether to transfuse or not was sometimes very difficult

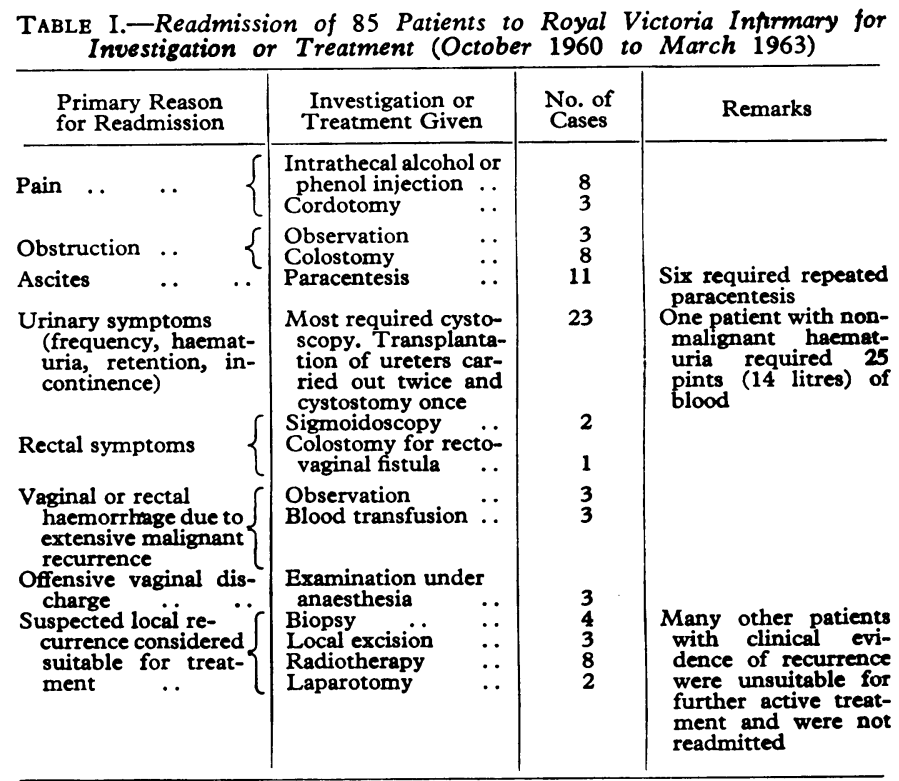

to make. Other patients were readmitted with symptoms due to extensive secondary growth in the pelvis or abdomen, and the choice lay between heavy sedation or active intervention; some were in very poor condition. In these cases, and in others, we believe that the doctor in charge must accept responsibility for the decision about how and to a certain extent when the patient is to die. The guiding principle in our opinion is that the patient should be helped to secure a peaceful ending ; if medical or surgical treatment will give relief in the terminal stages then it is justified. On the other hand, if intervention simply extends or aggravates a period of suffering and distress then we think this unkind both to the patient and to her relatives.

\section{Requests for Permanent In-patient Care}

Apart from emergency admission to hospital there were 34 requests for permanent in-patient care, mostly in the terminal stages, when relatives felt unable to meet the patients' needs ; in 27 cases admission was arranged to the hospitals shown

in Table II. Five died before admission, and at the time our 
survey finished two other patients were awaiting terminal-care beds. In most cases the waiting period was one or two weeks, but some had several weeks to wait. The delay before admission was generally accepted as inevitable, and relatives and friends

TABLE II.-Permanent Admission to Hospital-Mostly Terminal Cases N.H.S. hospitals :

$\begin{array}{lllll}\begin{array}{l}\text { Royal Victoria Infirmary } \\ \text { Geriatric units }\end{array} & \ldots & \ldots & 4 \\ \text { Local hospitals } & \because & \because & \ldots & 4 \\ \text { Marie Curie Foundation : } & & & \end{array}$

$\begin{array}{lllll}\text { Conrad House } & . & . & & \\ & . & 16\end{array}$

did their utmost to help, knowing that it was for a limited period, but some families managed better than others. Two case histories illustrate this point ; both patients were on the waiting-list for five weeks.

The first, a widow aged 72 , had an extensive cervical carcinoma which was treated palliatively with radiotherapy, but her condition deteriorated rapidly. Her three-bedroomed house, in a reasonable district, was privately owned; a son, his wife, and three schoolchildren also lived in the house. The son and daughter-in-law had full-time jobs and were out all day and seemed unwilling to put themselves to any trouble. The house was unkempt and the bedclothes were filthy, but the patient consistently refused to have the district nurse or a home help ; she wanted no stranger in the house. Whilst waiting for a terminal-care bed she had a brisk vaginal haemorrhage and developed a vesico-vaginal fistula. On admission she was exceedingly dirty and unkempt, but she was very grateful for the comparative comfort of her last few weeks in hospital before she died. The second patient, aged 69 , also had an extensive untreatable cervical cancer with urinary retention. She lived with her elderly semi-invalid husband in a council house, and two married daughters, both with young families, lived near by ; one daughter worked part-time. In spite of their own family commitments these daughters spent alternate days helping in the patient's home. A home help did two hours every morning and the district nurse came twice daily. As the situation became more difficult arrangements were made for a night nurse to come three times weekly. The patient was a devout Catholic; her priest visited her daily and obviously provided great solace and comfort; she died at home, five weeks after her name had been put on the waitinglist for a terminal-care bed.

National Health Service beds are not readily available for terminal cases ; there is a natural reluctance to admit a patient whose needs are nursing rather than medical and who may linger for several weeks, thus blocking the admission of urgent cases requiring essential treatment. For these patients we found the local cottage hospital more suitable than a large general hospital ; the atmosphere is informal and friendly, and the staff are often personally known to the patient and her relatives, who are within easy reach for visiting. Our city is fortunate in having a 40-bedded hospital run by the Marie Curie Foundation specially for cancer cases. As well as terminal cases this hospital deals with convalescent patients and those coming from long distances for out-patient radiotherapy. The 16 patients admitted were visited regularly by M.R. M., who found the atmosphere friendly and surprisingly cheerful.

We were assured by many general practitioners that the need for terminal-care beds was greater than we were able to show. They were well aware of the difficulty of finding suitable beds for these patients and sought admission only for those whose physical condition and home circumstances demanded urgent help ; were more beds available then other patients with less urgent but very real physical and social problems would be referred for admission. Some doctors suggested that the burden on relatives and friends would be greatly reduced if patients, during the last few months of their lives, were given in-patient care for periods of two or three weeks. The change of scene would benefit the patients and give their friends at home a much-needed rest.

\section{Place of Death}

Most patients who died were in their own homes at the end (Table III), and in many ways this might appear to be the most favourable arrangement, but this is a personal matter and circumstances differ from case to case. Some women clearly derived great comfort from known surroundings at home, but it would have been better for others to have died in hospital. In general we found that relatives were helpful, especially when the patient was in the younger age-group with dependent children. Elderly patients presented a problem; their daughters were often working from financial necessity or were fully occupied in looking after their own children. We found that the relation between patient and family was a reflection

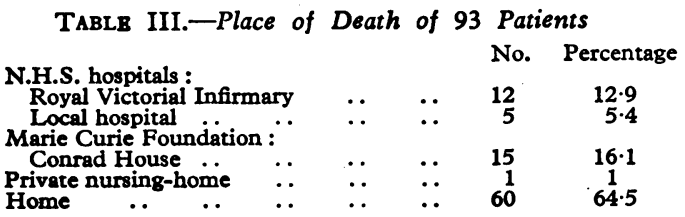

of the relations prior to illness. For example, two of our patients were elderly cantankerous widows who lived on their own. Their relatives refused to have them in their homes, maintaining that they had long been a disruptive influence and a cause of family friction. Under stress the personal relations within a family are sharply accentuated. Where there is strife, ill-will, or malice the care of the dying introduces an intolerable burden, with further hardship for all. But much can be done in the secure atmosphere of a well-organized, happy household. Some families arranged small informal parties in the patients' homes, and others had the local hairdresser come regularly to the house ; patients looked forward eagerly to these events.

Repeatedly we were impressed by the responsible share that good neighbours took in the care of those dying at home. This applied particularly to the poorer section of the community where families lived at close quarters and there was a great deal of coming and going between houses. But some of our patients in better circumstances and living in their own homes in suburban areas were barely acquainted with their neighbours. In several cases this pattern of suburban life with its sense of independence led to loneliness and real distress during the last few months of life.

We did note, however, that there was a limit to what good neighbours would do. They could be most helpful over emergencies and for periods of a few weeks, but their interest and support became less noticeable in time.

Of the 60 patients who were cared for and died in their own homes 41 made full use of the district nursing service and three made private arrangements with friends who were trained nurses. We were surprised to find that arrangements for a night nurse were made in only three cases. The patients who made little or no call on the nursing services were reluctant to have a stranger for the very personal (and to them rather embarrassing) type of nursing required; they preferred to rely on relatives and on well-known friends. One elderly independent woman steadfastly refused any outside help until she was exceedingly weak, when she induced a friend, a business woman, to move in with her domestic help. At this point she also summoned a male relative home from Africa to help with the night nursing.

Home helps were obtained in 9 out of 60 cases, and a further five families made private arrangements for extra domestic help. Various nursing aids were procured from local authorities and six families received financial assistance from the Cancer Relief Fund.

\section{Religion and Terminal Care}

It was not our purpose to examine closely the part played by religion in the terminal stages of the lives of these women. The subject was never deliberately brought up by us in our 
discussion with patients, relatives, or friends, but we couldn't fail to observe that in three homes, all Roman Catholic, patients and their relatives derived great spiritual help and comfort from the frequent visits of a priest.

\section{Conclusions}

In a limited way we have attempted to look at some of the social, medical, and nursing problems faced by women dying of pelvic cancer. From our base in a large teaching hospital we have looked outwards into the community we serve, but we are aware of our limitations and realize that others in closer and more continuous contact with patients in their homes could add much to what we have to say. We hope that they will be stimulated to do so.

On the whole our study leaves us with a sense of uneasiness. Compared with the costly and detailed investigation and treatments carried out initially in hospital we believe that too little attention is paid to the management of these patients in the terminal stages and to the peculiar difficulties they and their families face. Hardship for patients and their relatives could be eased if more beds of the right type were made available. We can see little point in patients with terminal cancer occupying beds in large, expensive hospitals ; quite apart from cost, we have known some of these patients to be intensely lonely in the middle of a busy acute ward. Beds for these cases are better sited in small local or cottage hospitals where family doctors can give the necessary supervision. We think it a pity that medical students do not have the chance to follow this type of patient out of hospital into the home so that they can observe, over a period, the harrowing preliminaries to death. There is so much for the student to learn about how to deal with patients and their relatives under stress, about the various agencies that can be called upon for help, and about the measures that can be taken to relieve pain and distress. These are matters of the greatest importance to all who practise medicine. But teaching hospitals have identified themselves with the management of acute illness rather than with the care of the chronically ill and the dying, and there is little opportunity for students to see or appreciate the sort of problem we have studied over the past three years. This failure is one of the important deficiencies of medical education to-day.

We were privileged to be allowed to observe these patients, and their relatives and friends, in their own homes during a period of great stress; their courage impressed us deeply. We are most grateful to the many family doctors and district nurses who gave us access to the homes and helped us in other ways. We should also like to thank the North of England Council of the British Empire Cancer Campaign for the generous grant which made the study possible.

\title{
Five Years' Experience With the Vacuum Extractor*
}

\author{
J. A. CHALMERS, $\dagger$ M.D., F.R.C.S., F.R.C.o.G.
}

Like so many " new" instruments the vacuum extractor has a long history of evolution. The Malmström instrument, now so widely used, represents merely a stage, albeit a highly efficient stage, in a story going back to 1704 (Yonge, 1706-7). The development of the method is still going on, and a number of newer instruments are becoming available. The Malmström instrument itself is undergoing modification. Evelbauer (1961), Rüther and Sokol (1961), and others have described electric pumps which they claim have made induction of the appropriate vacuum both easier and quicker.

At Worcester we have employed two different foot-pumps, the first derived from a Smith-Clark suction apparatus, and the second a stirrup attachment (see Fig.) devised by Malmström and Uddenberg and sent to us for trial. The object in both cases is, of course, to place induction of the vacuum under the control of the operator and to obviate the need of an assistant for this purpose. This may be an important advantage, particularly in domiciliary practice. In Rumania, Dragotescu and Roman (1962) have described their instrument, the "videx," which resembles the Malmström extractor in the form of the cup, but is fitted with a foot-pump and incorporates a vacuumrelease button in the traction handle. Chertkoff (1961), of Argentina, has also described a new instrument, the "ventosa extractora fetal " with a modified form of cup, which incorporates an electric motor operated by a foot-switch. It seems that we may look for further modifications and new instruments in

* Read to a ioint meeting of the Section of Obstetrics, Gynaecology, and Child Health and the Section of Physiology and Biochemistry at the Annual Meeting of the British Medical Association, Oxford, 1963. f From the Obstetric Unit, Ronkswood Hospital, Worcester. the future, but there is no doubt that it is the Malmström instrument which in the past seven years has shown obstetricians all over the world what a valuable contribution the

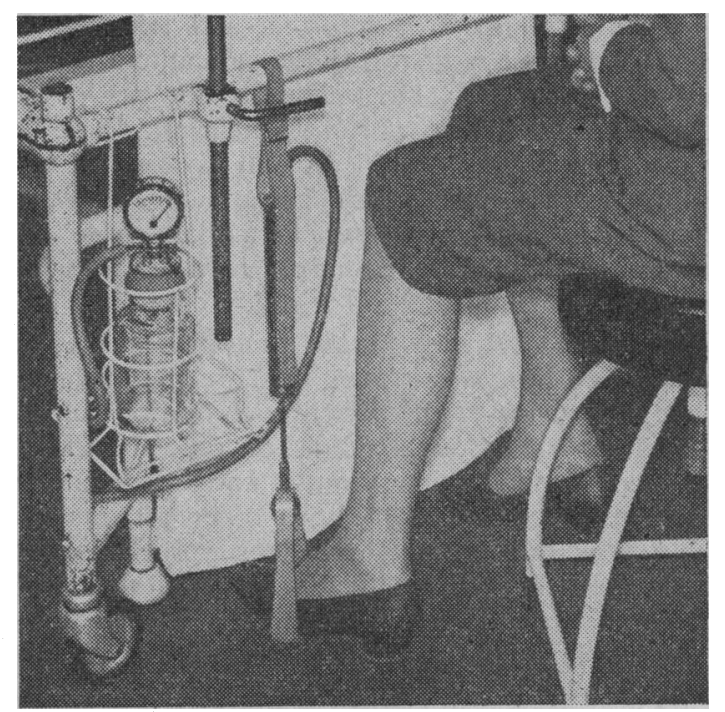

Stirrup-pump attachment for Malmström extractor.

vacuum extractor can make to many of the most difficult problems of obstetrics.

It was in the autumn of 1957 that Snoeck and Wilkin, in Brussels, first introduced me to the Malmström instrument, and 